\title{
Methods of graphical analysis of production processes
}

\author{
Marcin ROMANOWSKI, Krzysztof NADOLNY
}

DOI: 10.30464/jmee.2018.2.1.33

Online: http://www.jmee.tu.koszalin.pl/download_article/jmee_2018_01_033042.pdf

Cite this article as:

Romanowski M., Nadolny K. Methods of graphical analysis of production processes. Journal of Mechanical and Energy Engineering, Vol. 2(42), No. 1, 2018, pp. 33-42.

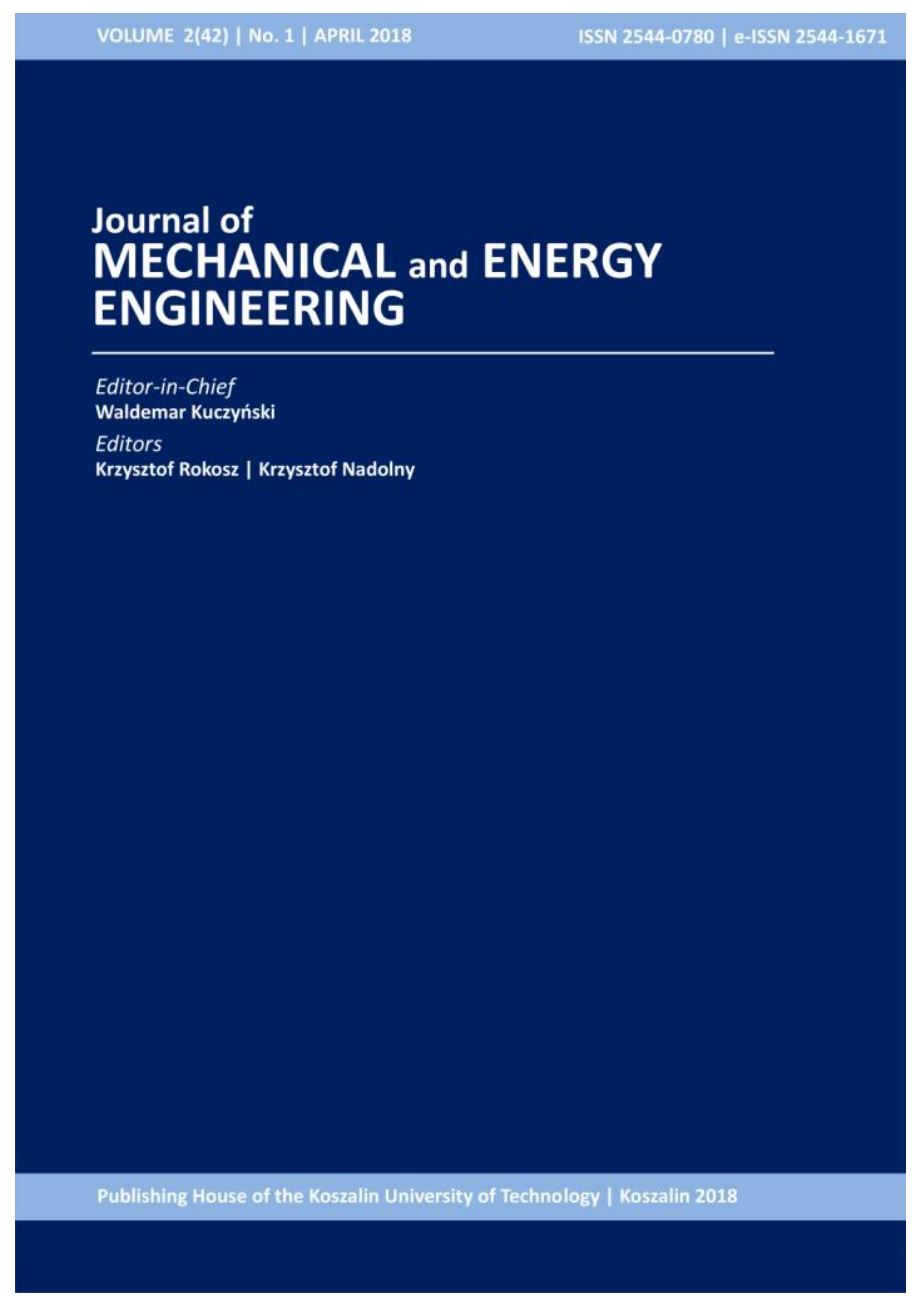

Journal of Mechanical and Energy Engineering

ISSN (Print): 2544-0780

ISSN (Online): 2544-1671

Volume: 2(42)

Number: 1

Year: 2018

Pages: 33-42

Article Info:

Received 2 February 2018

Accepted 27 February 2018

\section{Open Access}

This article is distributed under the terms of the Creative Commons Attribution 4.0 (CC BY 4.0) International License (http://creativecommons.org/licenses/by/4.0/), which permits unrestricted use, distribution, and reproduction in any medium, provided you give appropriate credit to the original author(s) and the source, provide a link to the Creative Commons license, and indicate if changes were made. 


\title{
METHODS OF GRAPHICAL ANALYSIS OF PRODUCTION PROCESSES
}

\author{
Marcin ROMANOWSKI ${ }^{1 *}$, Krzysztof NADOLNY ${ }^{2}$ \\ ${ }^{1 *}$ Faculty of Mechanical Engineering, Department of Production Engineering, Koszalin University \\ of Technology, Raclawicka 15-17, 75-620 Koszalin, Poland, e-mail: marcinro@wp.pl \\ ${ }^{2}$ Faculty of Mechanical Engineering, Department of Production Engineering, \\ Koszalin University of Technology, Poland
}

(Received 2 February 2018, Accepted 27 February 2018)

\begin{abstract}
The article presents the review of mostly used methods of graphical analysis of production processes. In the text were briefly characterised all main type of methods of analysis of production processes including: traditional methods (time research and traffic research), comprehensive research, modelling and simulation-based methods and graphical methods. Graphical analysis methods such as: process mapping, value stream mapping, Ishikawa diagrams, schedules, Gantt's charts, Pareto-Lorenz's diagrams, spaghetti diagrams, production variety funnels, analysis of the decision-making point, and examples of their application were described.
\end{abstract}

Keywords: production process, analysis, graphical analysis

\section{INTRODUCTION}

The process is an orderly sequence of activities designed and organized to realize a specific product or group of products, but these products may change. It follows the principle of operation at certain intervals, however, in the variability of qualitative and quantitative characteristics. It covers not only the manufacture of different parts and the combination of finished parts, but also activities such as storage, transportation, technical preparation of production [6].

A characteristic feature of each undertaking is the strategy that allows to achieve the target set. Modern manufacturing companies are both organizational and economic units. The goal of each company is to achieve positive business and economic results. The entire production process should be cost effective, implemented with maximising the production effect. In order to achieve a positive result, the control process must be taken into account [6].

The production can be described as a spread over time activity which consists in the physical manufacture of the product [14]. P. Drucker [4] noted: „Manufacturing is not the use of machinery or tools for material processing, but the application of logic to the work process". The production process, on the other hand, is a set of deliberately undertaken activities that make the desired changes in the subject matter of the work affected by them gradually change. By combining, they cause the object to gradually acquire features that bring it closer and resemble the intended product [14].

Production processes can be divided into several types, due to their different meaning and functions [14]:

a) given the importance of the tasks performed in the organisation:

- basic processes - the result is a product subject to sale,

- auxiliary processes - supporting the basic processes, thanks to these processes the basic processes can be efficiently implemented (e. g. manufacturing of production aids);

b) on grounds of relevance to the organisation:

- strategic processes - basic, auxiliary and management processes, which influence the strategic success of the organisation,

- operational processes (non-strategic processes) processes which enable the organization to run its day-to-day operations (e. g. customer service, manufacturing, shipping);

c) due to its place in the value chain:

- innovative processes,

- operational processes,

- after-sales service processes. 
The essence of the analysis is to divide the whole into parts in order to learn the essence of the subject. The analysis is primarily about getting to know the interconnectedness and interdependencies and discovering the most important relationships. To sum up, analysis is a means of examining the essence of things [5].

\section{METHODS OF ANALYSIS OF PRODUCTION PROCESSES}

Methods of analysis of production processes include:

- traditional methods: time research and traffic research,

- comprehensive research,

- modelling and simulation-based methods,

- graphical methods.

\subsection{Traditional methods}

Traditional methods of analysis of production processes involve activities such as time testing. It consists in measuring the entire working time spent during the whole shift or a specific part of it, for example by taking a photograph of the working day. The purpose of this method is to determine the type and magnitude of working time consumption, in particular the type and magnitude of time losses, to detect the reasons for their occurrence and to develop a plan aiming at maximising the use of working time for productive work [14].

In addition to time research, traffic research is also important for rationalisation of operations, because when studying the working time of several employees, significant differences in the use of working time can be found in the same positions and similar conditions, in order to discover the cause, it is necessary to use a method of traffic research. The reason for these differences is the difference in working methods of individual employees. They differ from each other particularly in terms of accuracy, number and system of movements, and the aim of research is to improve working methods. Motion tests include: production process diagrams, micro-movement tests, motion path studies. However, there is a difference between these three types of traffic tests. It consists of the accuracy of research results and three different aspects of carrying out analyses. For a precise comparison of these three main types of studies, the same work should be analysed. The difference between them is that they show the process from other parties [7].

\subsection{Comprehensive research}

A compilation of studies of complex movement, time and nuisance of work is a "kinogram". In this comprehensive study, it is determined: the route that an employee must take when working in a single operation, the time needed to travel through particular road sections, the change of body position (kneeling, tilting, etc.) and the force spent on moving or lifting [7].

The analysis shall be carried out from the point of view of [7]:

- it is necessary to perform every movement or operation (it eliminates unnecessary operations and movements),

- sequence of operations (change of the order of operations may mean saving movement and reducing workloads),

- possibility of combining several operations (combination of two or more operations allows to reduce the number of movements),

- simplification (frequently, it is possible to reduce the workload by changing the work organisation at the workstation through the use of special tools and instruments).

Summary of production process analysis methods [8]:

- name of the method of analysis of the production process,

- mapping of the process course,

- supply chain reaction matrix,

- a funnel for diversifying production,

- analysis of the decision-making point,

- correlation matrix,

- brainstorming,

- multi-factorial vote,

- diagram of connections,

- analysis of root causes,

- cause-effect scheme,

- programme charts of the decision-making processes,

- Gantt's chart,

- critical path analysis (PERT),

- planning continuity analysis.

\subsection{Modelling and simulation-based} methodologies

Process analysis methods also use modelling and simulation. Modelling is the creation of real life chip models, taking into account the desired accuracy and modelling costs. A simulation is an artificial imitation of a process and reconstruction of a given phenomenon or process on the basis of its model. Currently, four methods of process modelling are known: physical modelling, statistical modelling, modelling with the use of artificial neural networks and physical and mathematical modelling, and in effect computer modelling. The models constructed are to be used for process analysis and, as a consequence, modelling for their optimization. Each of the above modelling methods requires a separate approach and each of the ways positively and negatively influences the final effect. However, a properly performed modelling method enables the object to be analysed and then controlled in order to obtain the intended effects. Each of the modelling methods apart from physical and 
mathematical modelling requires experimental research, which is always associated with significant costs and a long time of research [6]. By contrast, during the simulation, random values are obtained, but with a probability distribution and an average value. The data obtained corresponds to the actual process. The probability of a given phenomenon or process can be evaluated on the basis of simulations. Based on the results of this method, similar effects can be expected in real conditions.

\subsection{Graphical methods}

Graphical methods are defined by model schemes, depicting the way phenomena occur. The aim of creating such schemes is to analyse and improve existing solutions. These include process mapping methods, Ishikawa diagrams and Gantt schedules and graphs.

Process mapping is one of the most commonly used graphical methods. This term is understood as a visualization of process architecture, identification of processes in all aspects of management and recording them in the form of flow diagrams using specific symbols included in Table 1.

It consists in graphically illustrating the functioning of the process. The purpose of process mapping is not to describe the process accurately, but to understand it, which is the basis for making any changes. The basis for mapping is to determine the beginning and end of the process. In the next step, individual operations are drawn, which are connected together by means of arrows [14]. The most common input data for the process are the materials, information, plans from different levels of management and environmental conditions necessary for the process to proceed according to its objectives. The starting data may be a tangible, intangible or service product.

When mapping processes (Fig. 1) the company would have little advantage in mapping the status quo, and therefore the focus should be on mapping the future [13].

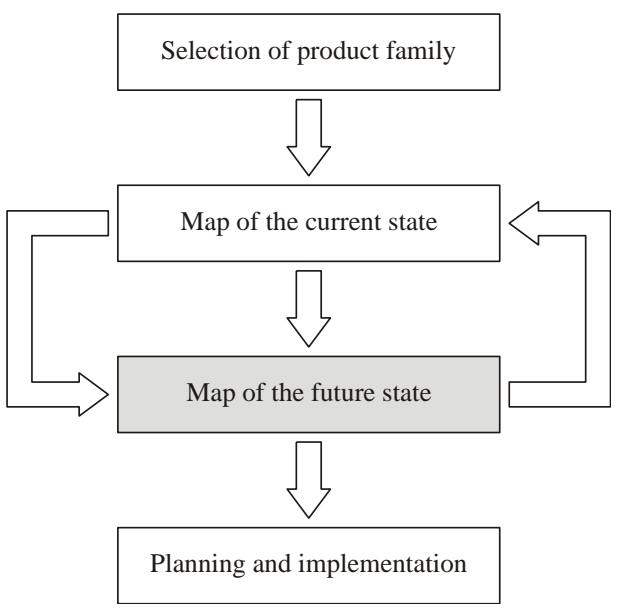

Fig. 1. Process mapping steps [13]
Tab. 1. Symbols used in describing production processes [9]

Start, end
Operation, task, activity, process stage
Onspection

In order to produce a map of the current situation, it is necessary to have information from the production. This will make it possible to map the future state of affairs. In the final stage, a plan should be prepared to be implemented in the company. The implementation of one plan forces the company to prepare another plan for the future [13]. An example of a process map is shown in Figure 2.

When mapping the process, remember that the purpose of the map is not to describe the process in detail but to understand it. This understanding enables us to make changes [14].

The process mapping takes place in two stages: identification and grouping. The first stage is divided into two methods:

- the top-down method, in which the organisation's activities and objectives are first defined, is then followed by a more detailed description of the above mentioned elements;

- bottom-up, more precise but more labourintensive, which is based on the analysis of the activities carried out and the formulation of the processes on their basis. 


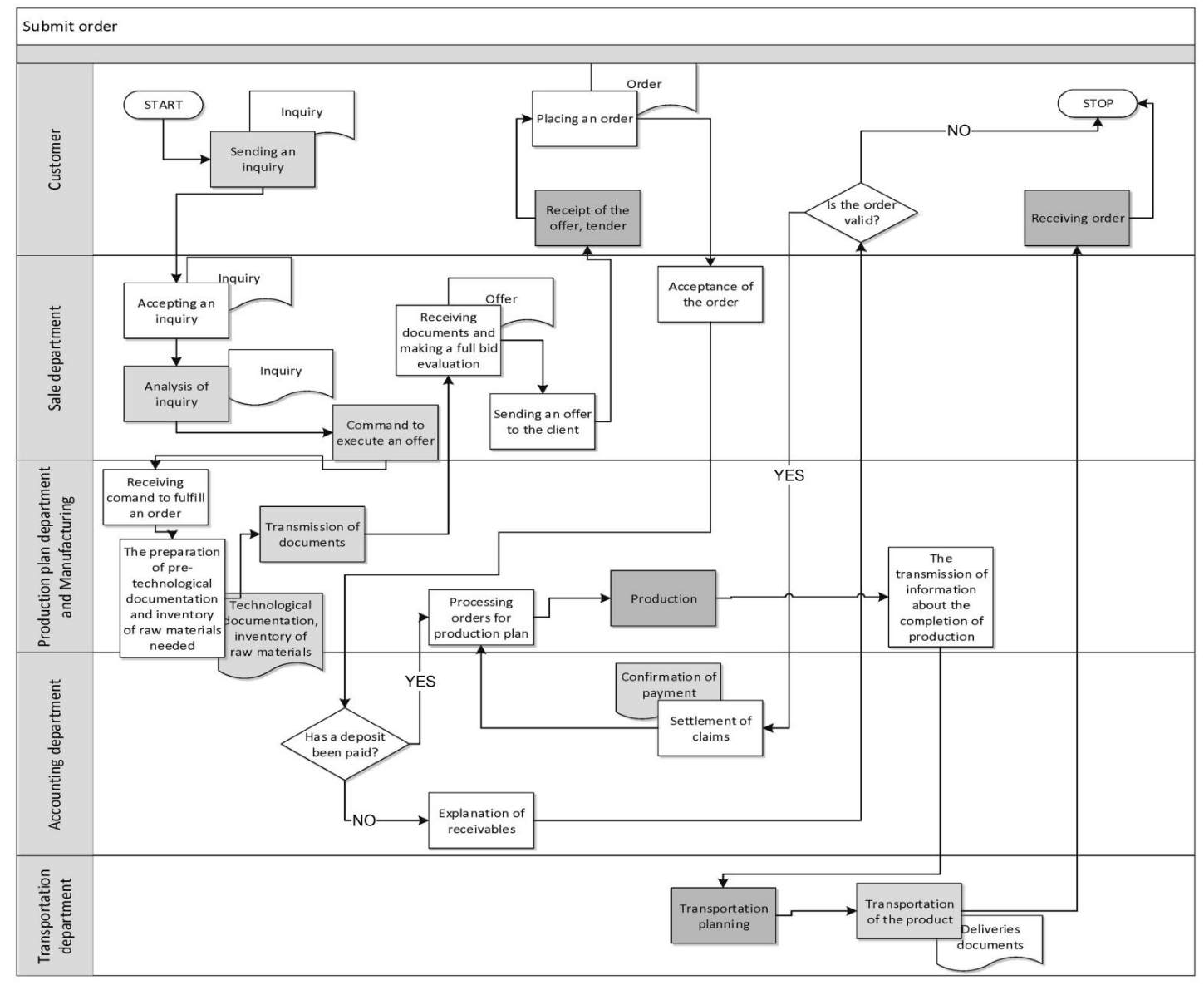

Fig. 2. Example of process map [2]

In the second stage, grouping into management processes related to mission, objectives, strategy and position on the market, main processes related to the creation of the organization's results, as well as supporting processes related to the internal customer, e. g. recruitment, procurement [17].

Process mapping is used worldwide to analyse production processes. This is related to the advantages of this method, which can be classified as [17]:

- use of symbols, are known in many countries, which facilitates communication between various organizations from different parts of the world;

- key operations in a given process, and defining the necessary entrances and exits in a given operation;

- identification of unnecessary operations, such as storage of semi-finished products between operations, internal transport, etc.

Another related graphical method of production process analysis is value stream mapping (Fig. 3). It improves the flow of added value in an enterprise. It is used in both production and service companies. It is often referred to as a drawing of a block diagram illustrating, analysing and improving activities to deliver a product or service. By mapping the value stream, you can shorten the product's transition time through the process and increase the ability to respond to customer demand [18]. The method aims to eliminate waste and create the most efficient system.

Mapping a stream of values, just like other visualizations, serves as an effective tool for communication, collaboration and even changing the work culture. Decision-makers can clearly visualise the current state of the process and where waste is generated. Problems such as process delays, excessive downtime, restrictions and stock problems can also be seen [1]. The effectiveness of value stream mapping depends on simultaneous mapping of the material flow and the information linking it. The main purpose of Mapping a value stream is to identify and eliminate wastage that lengthens the so-called Lead time, the time of product passing through the process until it is delivered to the customer [19].

The Ishikawa diagram, on the other hand, allows for a graphical presentation of the group of factors that influence the final result of the process. The main purpose of this method was to identify the relationship between supplier and customer. 


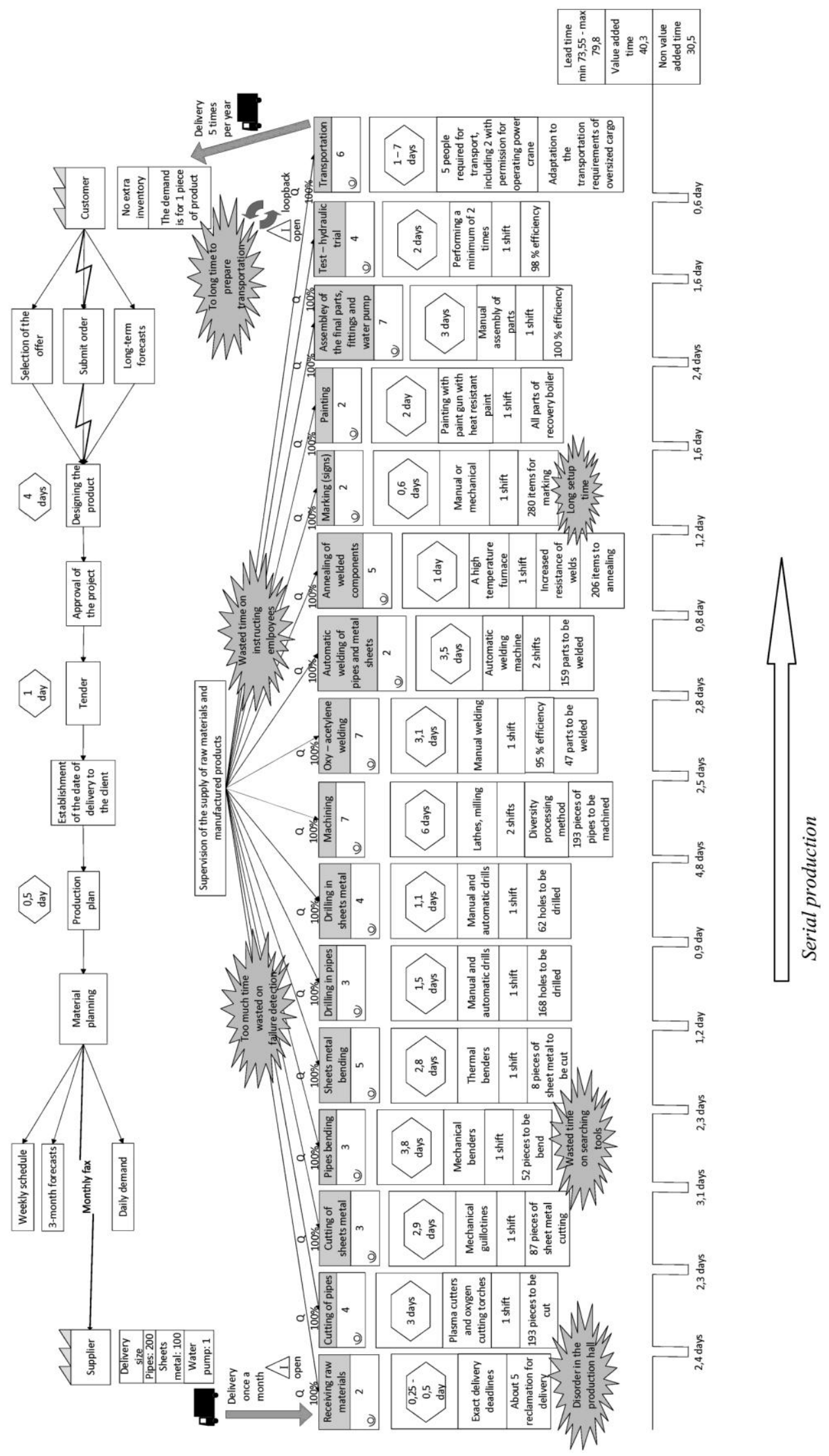

Fig. 3. Example of value stream map [2] 
The user shall designate appropriate quality characteristics of the selected product in accordance with the consumer's expectations. The interview allows us to select errors and their causes and determine the expectations of the future customer [10]. It is assumed that the effect is not the result of a single factor, but of multiple factors. Due to its appearance (Fig. 4), it is also referred to as' fish bones'. The causes are shown on the shoulders of the diagram and the effect is described on the spine. The causes are usually divided into five groups: machine, method, material, man and management [14]. Using the Ishikawa diagram, they should be defined and arranged [7].

The diagram of Ishikawa, shown in Figure 4, should be prepared [7]:

- draw the main axis in the form of a horizontal line, ending with a cave describing the main problem,

- on the shoulders, which are a branch of the main axis, write out the causes causing the effect,

- by answering questions, why, how? complete the diagram with new branches in order to list all reasons for the situation.

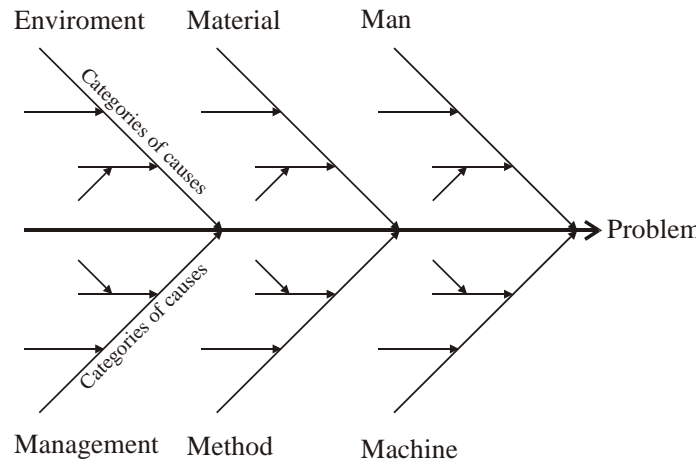

Fig. 4. Ishikawa's Diagram [15]

Ishikawa's diagram is very helpful in management. It allows you to visualize the problem with possible causes in an easy and quick way. It also gives the possibility of separating effects from causes, and recognizing the complexity and complexity of the analysed problem. The implementation of such a diagram should take place in a group, using, for example, the "brainstorming" method [14]. The fish bone diagram analysis procedure requires a number of stages of its development. The first and most important phase is to determine the problem, which will be represented by the main horizontal axis of the diagram. Next, the main groups of causes that cause the problem should be identified, e. g. in the group of material causes it may be their poor quality. The third stage is detailing in those groups that were presented at an earlier stage. In this case, the weak bones may be caused by the low budget for their purchase. In the final stage, the diagram should be carefully analysed. The process of creating the Ishikawa diagram is repeated until all possibilities of determining the causes of the problem have been used [16].

Scheduled production schedules are another method that graphically illustrates the production process. These are graphical diagrams showing the chronological course of action. Scheduling is used to present the activities following each other and those that occur simultaneously and are carried out by different organisational units [11].

Z. Mikolajczyk shows the following stages of scheduling [11].

1. Creation of an inventory of activities.

2. Measurement of the duration of the above activities in case of analysis of an already functioning process or estimation of the length of individual activities in case of designing a new one.

3. Building a table containing all the data.

4. Graphics development. Schedules are created on a graph where the time line runs horizontally and the actions of individual objects are vertically arranged.

Bold lines shall be drawn parallel to the time axis, reflecting the duration of each activity in chronological order.

If the process under review is complex, general and detailed timetables can be drawn up which also increases transparency.

General schedules show the group actions - the total time of these operations, which is represented by a single line.

Detailed timetables shall show the implementation of each activity in the group. Schedules are used in practice for programming and supervising the implementation of not complicated processes, mainly production processes [11].

Gantt's charts, on the other hand, graphically show the time relationships between individual stages of the process implementation, which is aimed at the realisation of a specific project. Gantt's charts allow comparing the work performed by a given contractor with a previously accepted plan. It becomes possible to identify the causes of possible deviations and to correct the plan. Gantt's charts should be constructed on the basis of graph columns indicating the assumed time periods and the size of planned tasks to be performed. Then the ratio of work to planned work is marked with a vertical line. Gantt's charts allow for a quick assessment of the project status at any given moment, as shown in Figure 5. If delays or other irregularities are detected, it is possible to correct them by: changing the workstation loadings or making the deadlines for the implementation of measures more realistic [11]. 


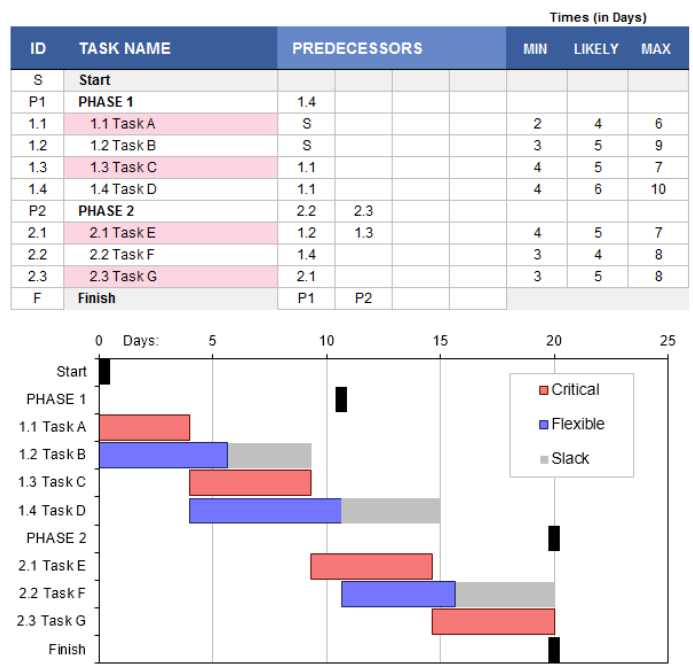

Fig. 5. Example of Gantt's diagram [22]

The Gantt's charts shall be used to draw up the diagrams:

- performance charts - indicating the degree of completion of previously planned tasks,

- graphs of the use of machines and equipment allowing to determine the production plan and its implementation taking into account the use of the production capacity of the possessed machinery and the time in which it can be used,

- Planning diagrams - allowing for such a planning of work in the enterprise, which will ensure its continuity, and will allow for an even load of workstations. It will also prevent or reduce downtime (used in the organisation of production processes and complex workflows) [11].

Gantt's schedules and graphs are used to plan and coordinate work processes, especially in small and medium-sized enterprises.

Another method of production process description is the Sankey graph (Fig. 6). It is a graph drawn up, for example, during the preparation of technological processes or individual operations. This diagram shows the parts of the system that are connected by means of the flow direction arrows. The arrow width is proportional to the flow of matter. Sankey's graph is used to prepare the balance of probable causes of events, e. g. product defects in production [23].

Another equally effective tool is the ParetoLorenz's diagram. It allows us to identify the most important factors affecting a given effect. An example diagram is shown in Figure 7.

The Pareto-Lorenz's Diagram is based on the principle that $80 \%$ of effects are caused by only $20 \%$ of causes [7].

Pareto-Lorenz's diagram should be prepared [7]:

- identify the factors influencing a given result,

- collect quantitative data about a given factor,

- the factors should be arranged in a decreasing order, taking into account the percentage share of a given factor in the final result,

- apply percentages to the graph.

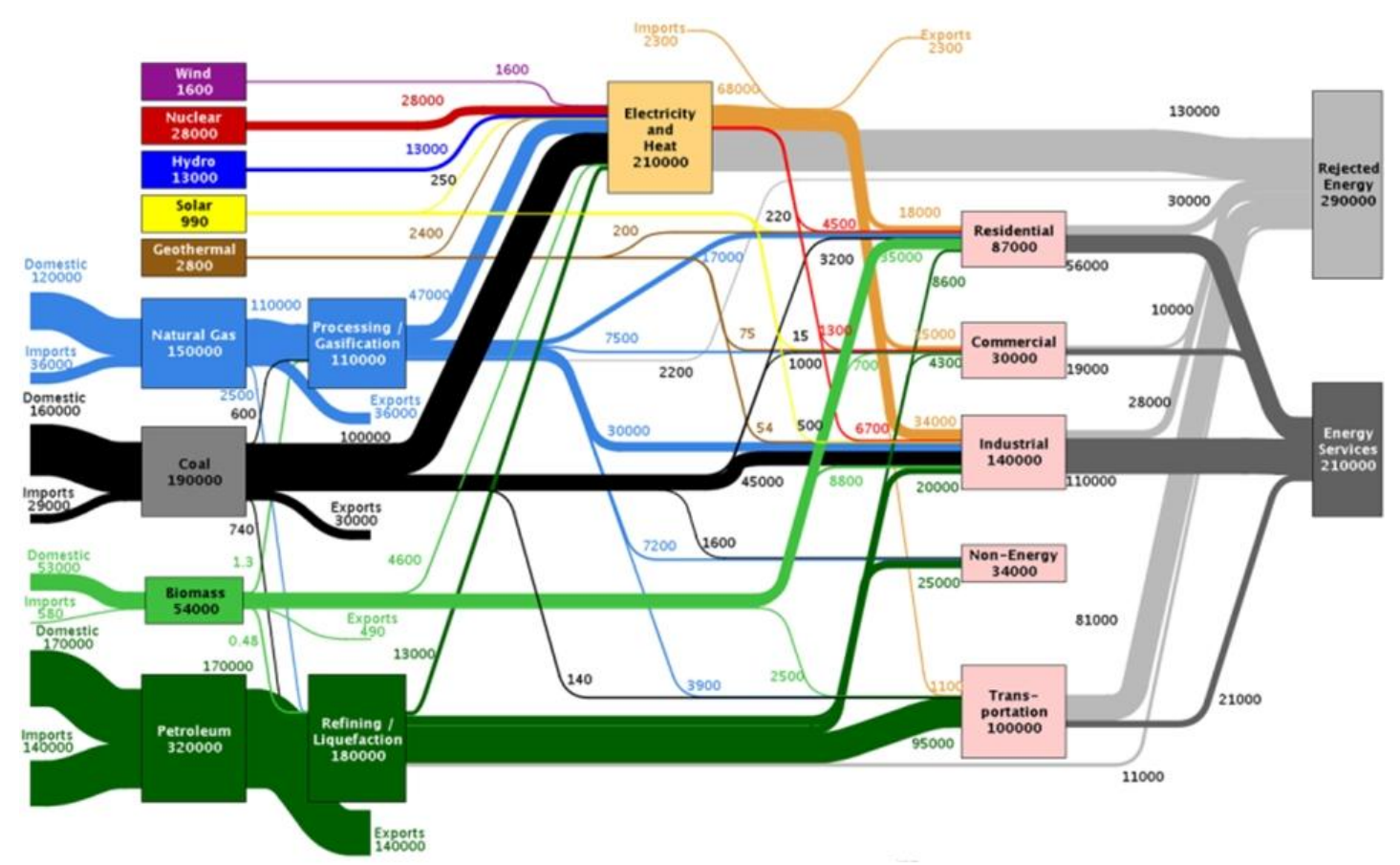

Fig. 6. Example Sankey's Chart [23] 


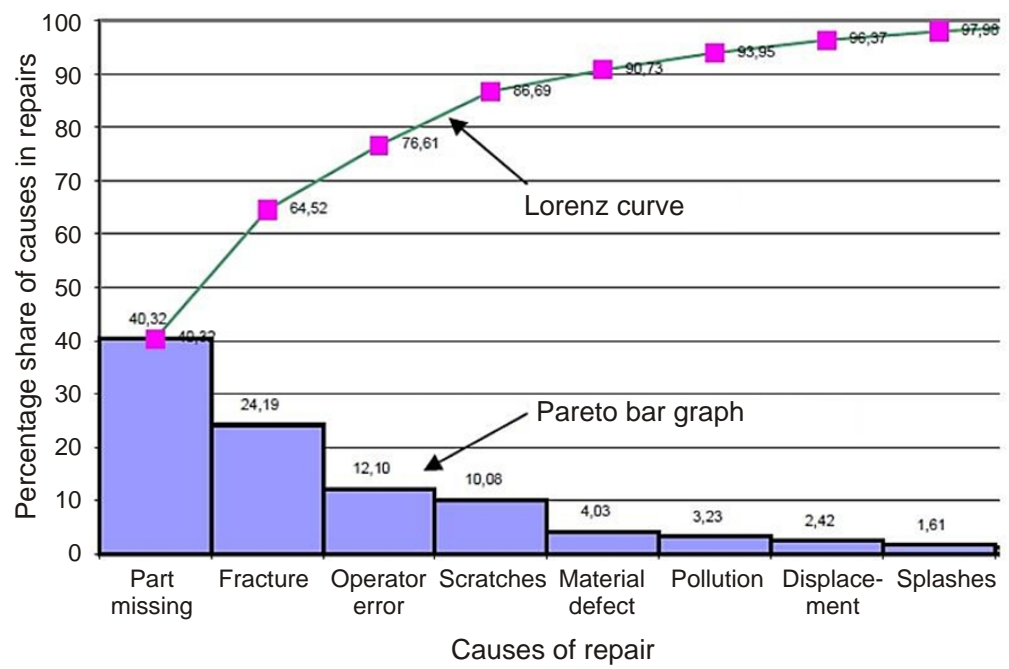

Fig. 7. Pareto-Lorenz's diagram [20]

An interesting solution is to use the spaghetti diagram. This is one of the lean methodologies. It is used to visualize material and product flows. When several diagrams are made, it is noticeable how complicated the product's transport paths are from the moment the raw material is introduced to the material production hall until the moment of the finished product's output. The example diagram shown in Figure 8 is created by applying on the plan of the plant the paths defined by the movement of the product during subsequent stages of production. Ideally, this flow will be physically tracked by the team that creates the diagram and the diagram will be made on a known scale. This will make it possible to present the movement of the product within the company's premises, as well as to calculate the distances covered [1].

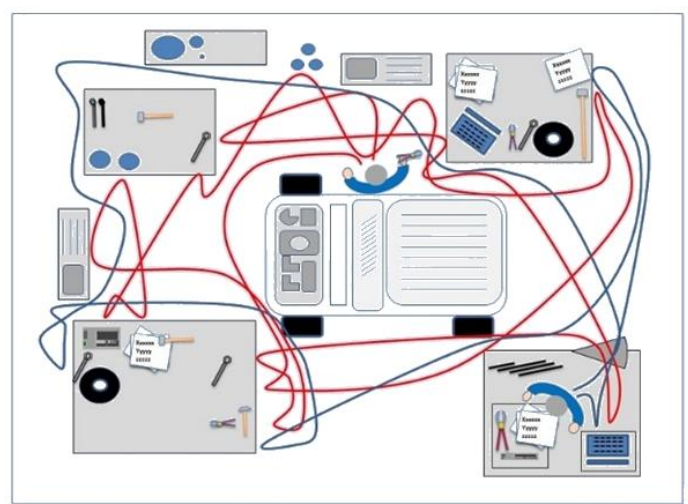

Fig. 8. Example of spaghetti diagram [21]

Based on the conclusions that can be drawn from drawing a graph, you can decide, among other things, on the basis of the graph:

- shortening of paths through which the material moves (e. g. choosing a shorter distance),
- transfer of workstations (if the material is moved back and forth,

- frequency of movements between particular positions,

- size of production/transport batches,

- elimination of unnecessary activities (especially carrying, packaging, unpacking, moving empty containers, etc.),

- relieve the load on the most frequently used intersections and transport paths,

- improvement of internal transport,

The spaghetti diagram can be used as a standalone tool, especially in organisations with less complex processes. However, it is usually used in the initial phase of analysis and used in more advanced tools at a later stage [1].

The next instrument for analysing production processes is the chimney of production variety funnel. Figure 9 shows the chimney of supply chain diversification [3]. It graphically presents the degree of diversification of assortment of raw materials, materials, parts, sub-assemblies and finished products in subsequent stages of the value creation process.

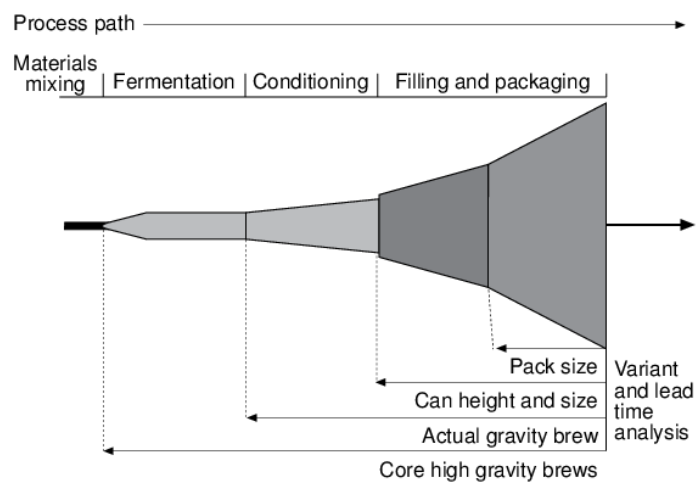

Fig. 9. Production variety funnel $-\mathrm{a}$ brewing industry case [8] 


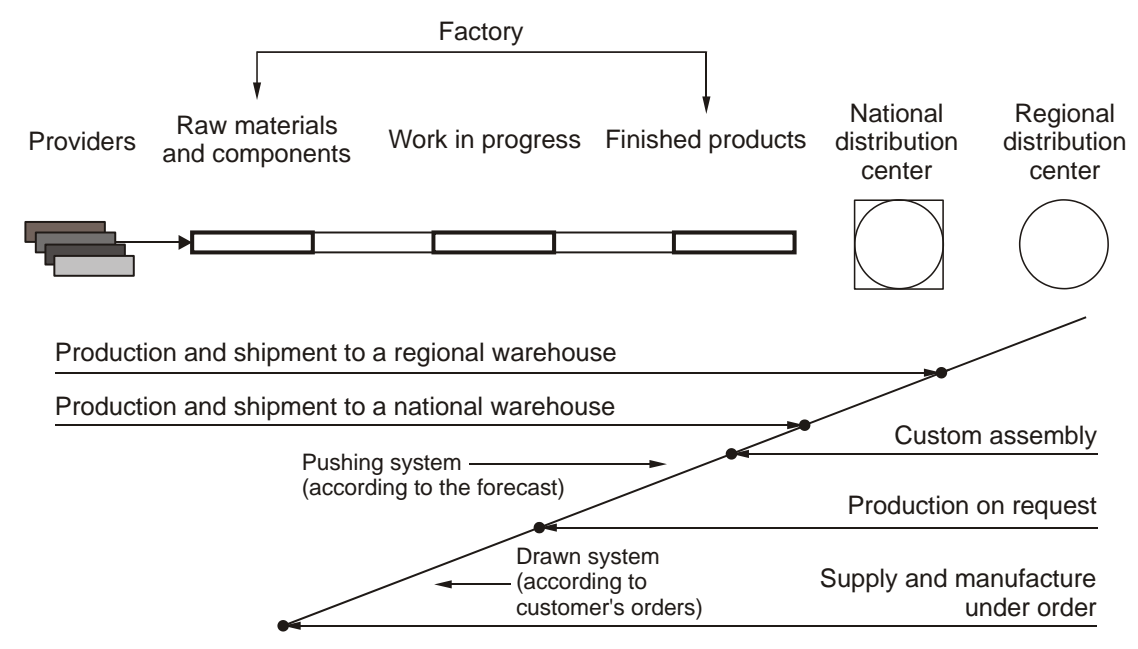

- Decision-making center of the supply chain

Fig. 10. Analysis of the decision-making point [8]

It consists of graphically presented degree of difference in assortment of raw materials, subassemblies, finished products and materials during subsequent stages of value determination process. This method makes it possible to understand the complexity of the company's supply chain [3].

Another method is the analysis of the decision/ cross-border point, which motivates actions resulting from the map of strengthening demand for a given product, especially for industries representing chimneys of diversified production with a complex combination of finished products, which are manufactured from a small number of components [8]. This example is shown in Figure 10. This point is based on the enrichment of log file entries and additional information on process environments. Important data for the process are needed to establish decision-making rules for alternative branching in process models. In the first step, the underlying process was discovered. If the resulting process model contains decision points, the relevant decision-making rules are analysed with the use of decision trees (data mining).

The decisive point is the place where actual customer demand meets the expected sales volume [8].

\section{CONCLUSIONS}

The paper presents methods enabling to graphically assess the actual state of the company's production process. Graphical analysis methods such as: process mapping, value stream mapping, Ishikawa diagrams, schedules, Gantt's charts, Pareto-Lorenz's diagrams, spaghetti diagrams, production variety funnels, analysis of the decision-making point, and examples of their application were described. The main conclusions drawn from this information are as follows.
1. Graphical methods showing production processes are very helpful in the analysis of a given process and indicate the place where wastage occurs (concerning time or resources).

2. Production analysis is extremely important in order to achieve the right tempo and reduce unnecessary costs.

3. Every production process has different levels of complexity, which complicates the selection of methods of its analysis, therefore different methods are used to assess the processes.

4. Due to the unambiguously defined duration of activities constituting a given project, the described methods are suitable for use in planning of not very large and, above all, relatively short projects in progress.

5. application of the presented methods for graphical analysis of processes in an intuitive way allows to identify the existing problems and to develop methods of overcoming them, which in turn brings measurable financial benefits to the enterprise.

\section{References}

1. Bicheno J. (2004) New Lean Toolbox: Towards Fast Flexible Flow. PICSIE Books, pp. 7-9.

2. Baczkowicz M. (2014). Using value stream map and process mapping for visualization recovery boiler OS-5 production. Management of Entrepreneurship Journal, No. 3/2014.

3. Ciesielski M. (2006) Instruments of Logistics Management. PWE, Warsaw. (in Polish)

4. Drucker P. F. (2005) Management Practice. MT Bussines, Sp. z o. o. (in Polish)

5. Gawlik J., Plichta, Swic A. (2013) Production processes. Polish Economic Publishing House. (in Polish)

6. Gotowala K., Patyk R. (2016) Application of modern modelling and simulation methods in the design of machines and devices. Bus conference materials, no. 8/2016. (in Polish)

7. Hamrol A. (2013) Quality Management Theory and Practice. PWN Scientific Publishing House. (in Polish) 
8. Hines P., Rich N. (1997) The Seven Value Steam Mapping Tools. International Journal of Operations \& Production Management, Vol. 17, No. 1, p. 53.

9. Lewandowski J. (2014) Organization of production systems, PWE, Warsaw. (in Polish)

10. Ladonski W., Szoltysek K. (2008) Quality management Part III. Publishing House of the Academy of Economics in Wroclaw, 13/15, 62/63, 72/77, 81/89, 90/, 99/105. (in Polish)

11. Mikolajczyk Z. (1998) Organizing techniques in solving management problems. PWN, Warsaw, p. 280. (in Polish)

12. Romanowski M., Nadolny K., Sutowski P. (2017) Value stream mapping of the production process of tankers for the transport of liquid food stuffs. Journal Mechanical and Energy Engineering, Vol. 1(41), No. 2, pp. 123-128.

13. Rother M., Shook J. (2003) Learning to see. Lean Enterprise Institute Publication, pp. 10-20.

14. Slowinski B. (2009) Logistics Process Management Engineering, Publishing House of Koszalin University of Technology. (in Polish)

15. http://4pm.pl, (Access: November 2016)

16. http://www.cel proces.pl, (Access: April 2015)

17. http://www.governica.com, (Access: May 2015)

18. https://lean.org.pl/ (Access: January 2018)

19. http://leanactionplan.pl/mapowanie/ (Access: January 2018)

20. http://octigo.pl, (Access: February 2016)

21. http://www.printablediagram.com/printable-spaghettidiagrams/, (Access: January 2018)

22. https://www.vertex42.com, (Access: January 2018)

23. http://whatnext.pl, (Access: May 2016)

\section{Biographical notes}

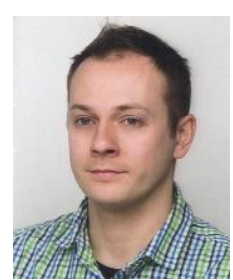

Marcin Romanowski received his M.Sc. degree in Exploitation Port and Fleet (specialisation: transport) from Maritime Academy in Gdynia. He works as Logistics and Procurement Manager in PRO-WAM Company in Koszalin and simultaneously studies at second year of Ph.D at the Koszalin University of Technology. $\mathrm{He}$ is interested in cost minimalization and technological foresight.

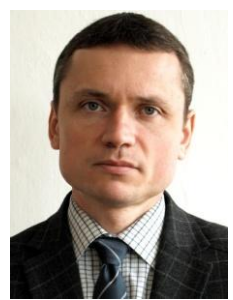

Krzysztof Nadolny received his M.Sc. degree in Mechanics and Machine Design and next Ph.D (with honors) as well as D.Sc. degree in Machinery Construction and Operation from Koszalin University of Technology, in 2001, 2006 and 2013, respectively. Since 2006 he has been a researcher in the Department of Production Engineering at the Koszalin University of Technology, where currently he works as an associated professor and head of research-didactic team for production planning and control. His scientific interests focus on problems concerning machining processes and tools, efficiency, monitoring and diagnostics of machining processes as well as tribology. $\mathrm{He}$ has participated in 2 international and 3 national research projects, presenting results of his work at 10 international and 21 national conferences, published more than 200 scientific papers in international and national journals, book chapters, as well as conference proceedings. He is also the author of 4 monographs and 9 national patents. 